\title{
Consolidando la política de inversiones por medio de la Cláusula de Nación más Favorecida en los Tratados Internacionales de Inversión
}

\author{
Consolidating investment policy through the \\ Most Favored Nation Clause in International \\ Investment Treaties
}

Carlos Riquelme*

\section{Resumen}

La Cláusula de Nación más Favorecida ha recibido mucha atención en el régimen internacional de inversiones en los últimos años. Las discusiones han girado respecto de si dicha disposición permite atraer condiciones más favorables relativas a la solución de controversias. Este trabajo se aleja de dicha discusión y analiza otro problema que ha contado con menos atención. Se refiere, particularmente, a la posibilidad de que por medio de dicha cláusula se atraigan condiciones más favorables contenidas en tratados celebrados previamente. Esa posibilidad es de interés, pues la misma podría hacer difícil la modificación de la política de atracción de inversiones de los Estados plasmada en sus tratados de inversión. Si se con-

Abogado, Universidad de Chile. Postítulo en Economía y Finanzas para Abogados de la Facultad de Economía y Negocios de la Universidad de Chile. L. L. M. en International Law, Ruprecht-Karls-Universität Heidelberg y Universidad de Chile. Investigador Universidad Academia de Humanismo Cristiano, Chile. Mail: criquelmer@academia.cl Recibido: 24 de noviembre de 2015. Aceptado: 14 de marzo de 2017. 
sidera que eventuales giros en la estrategia de desarrollo son deseables, la cláusula constituye un obstáculo el cual debería ser analizado con detención.

Palabras Clave: Cláusula de Nación más Favorecida - Inversión Extranjera - Política de Desarrollo - Tratados Bilaterales de Inversión - Multilateralismo.

\section{Abstract}

The Most Favored Nation Clause has attracted much attention in the international investment regime in the past years. The debate has centered on whether such regulation allows the attraction of more favorable conditions regarding the resolution of controversies. This paper moves away from this debate to analyze another problem that has gained much less attention: the possibility that, through said clause, more favorable conditions included in previously signed treaties are attracted. This possibility is of great interest since it could hinder the modification of the investment attraction policies of the States as expressed in their investment treaties. If eventual shifts in the development strategy are desirable, the clause constitutes an obstacle that should be thoroughly examined.

Keywords: Most Favored Nation Clause - Foreign Investment - Development Policy - Bilateral Investment Treaties - Multilateralism. 


\section{INTRODUCCIÓN}

Los Tratados Bilaterales de Inversión (o Acuerdos de Promoción y Protección Recíproca de Inversiones) son Tratados Internacionales entre Estados, que otorgan determinadas garantías en favor de los inversionistas extranjeros en el territorio del Estado que recibe sus inversiones (razón por la cual este pasa a denominarse "Estado receptor"). Sus disposiciones, particularmente favorables a la actividad de los inversionistas foráneos, comprenden tanto la definición de la inversión protegida por el Tratado; cláusulas que resguardan a los inversionistas en caso de expropiación o de medidas expropiatorias; estándares como el de trato justo y equitativo o el de trato de nación más favorecida; así como un mecanismo de solución de controversias (arbitraje) entre el Estado receptor y el inversionista extranjero (Sornarajah, 2010).

La importancia de las disposiciones mencionadas ha crecido en la medida que gran parte de los Tratados de Libre Comercio las ha reeditado en sus respectivos capítulos de inversiones. Así, la posición privilegiada de los inversionistas extranjeros se ha expandido y extendido en un sinnúmero de instrumentos internacionales de diversa naturaleza.

Como se dijo, esta posición privilegiada se nutre específicamente de los estándares de trato justo y equitativo, y por el de trato de nación más favorecida. Este último, incorporado en los Tratados Internacionales por medio de la Cláusula de Nación Más Favorecida (CNMF), es de particular interés pues, como se verá, permite extender las condiciones en las cuales operan los inversionistas de un país a los de otro Estado, lo cual coadyuva en la generación de un marco competitivo que no discrimina arbitrariamente en base a la nacionalidad de los capitales involucrados.

En materia de inversiones, la CNMF ha sido objeto de una ardua discusión (académica, política y jurídica) en los últimos años ${ }^{1}$. Las controversias han girado específicamente sobre un problema particular: si el centro de gravedad de la cláusula en cuestión permite atraer, como la tierra atrae a la luna, no solo condiciones "sustantivas", sino también aspectos tradicionalmente considerados "adjetivos" por la doctrina, como son los mecanismos de solución de controversias. En este caso, no solo han sido los académicos los que se han posicionado en veredas opuestas, sino también la jurisprudencia ha destacado por sus decisiones divergentes. Las voces

1 Sin perjuicio de ello, Vessel subraya que las controversias en torno al alcance y sentido de la CNFM la persiguen desde su nacimiento (Vessel, 2007). 
más críticas en la materia han resaltado el efecto "desestabilizante" que esto podría causar al ya sensible régimen internacional del derecho de inversiones (Egli, 2007).

Sin desconocer la importancia de dicho debate, este trabajo tratará de otorgar ciertas luces a otra dimensión contenida dentro de los pilares estructurales de la CNMF, dimensión que, por lo demás, ha pasado casi inadvertida entre los comentaristas (salvo honrosas excepciones, las cuales se revisarán posteriormente ${ }^{2}$ ). Así, nuestra pregunta de investigación es la siguiente: ¿cómo opera la CNMF en el tiempo? O más precisamente: ¿puede atraer condiciones establecidas en un Tratado previo, que sigue vigente? Lamentablemente para nosotros (y como veremos, por fortuna para los Estados receptores) el asunto aún no ha sido sometido a los Tribunales arbitrales del Centro Internacional de Arreglo de Diferencias Relativas a Inversiones (que es el foro que usualmente resuelve las controversias en materia de inversiones extranjeras), lo cual no implica en caso alguno que el asunto carezca de relevancia, como se tratará de mostrar en este artículo.

Antes de proseguir, ilustraremos el problema con un ejemplo que irá

2 Entre esas excepciones se encuentran: Vessel (Vessel, 2007), Cole (Cole, 2012), Schill (Schill, 2009) y Ishikawa (Ishikawa, 2015). adquiriendo claridad en las siguientes páginas.

Suponga que el Estado A ("Morulandia") requiere con urgencia atraer capitales extranjeros, por lo que inicia una campaña para promocionar la inversión dentro de su territorio. Para el efecto, entre los instrumentos de política pública, Morulandia decide impulsar un programa para suscribir tratados bilaterales de Inversión (o tratados de libre comercio con capítulos de Inversión) con terceros Estados. En tanto, Morulandia se encuentra convencida de los efectos benignos que este tipo de actividad tendrá en su economía, razón por la cual decide ofrecer condiciones increíblemente provechosas para los inversionistas extranjeros en dichos tratados, por ejemplo, garantizándoles que ellos puedan repatriar sus capitales cuando deseen, estableciendo un procedimiento administrativo particularmente sencillo para que eso pueda ocurrir. Sorprendidos por el compromiso de Morulandia con el progreso económico por medio de la iniciativa privada, varios Estados (entre ellos el Estado B, “Consistinia”, y el Estado C, "Plutorca") suscriben documentos con el primero, digamos, en el año 1991.

Diez años más tarde (es decir, en 2001), una crisis económica internacional golpea particularmente fuerte a Morulandia. Sin embargo, ni la severidad de aquella crisis 
pudo persuadir a los personeros de dicho país respecto de su orientación hacia el mercado mundial, razón por la cual redobló sus esfuerzos suscribiendo Tratados de Inversión con otros Estados (entre ellos, el Estado D, "Camingo"). Aun temiendo una eventual fuga de capitales, dado el delicado escenario internacional, Morulandia incluyó una limitación en el Tratado con Camingo (que no estaba contenida en los Tratados con Consistinia y Plutorca) relativa a la repatriación de capitales. Así, tanto las "salidas" de las inversiones como las utilidades caminguesas del territorio de Morulandia, se encontrarían sujetas al control del Banco Central de este último Estado. La cuestión fue considerada absolutamente razonable por el gobierno de Camingo, habida consideración del prestigio del Banco Central y del gobierno de Morulandia, en lo que se refiere a la actividad privada nacional y extranjera.

Sin embargo, el Tratado entre Morulandia y Camingo contemplaba una cláusula "de estilo", presente $3 / 4$ como señalamos más arriba $3 / 4$ en la mayor parte de los Tratados de Inversión suscritos en el mundo a esa fecha. La redacción de la cláusula no difería sustantivamente de los otros Tratados y disponía que Morulandia no podría otorgar un trato menos favorable a los inversionistas de Camingo que el que otorgase a los inversionistas de terceros Estados. La cláusula en cuestión no contemplaba ninguna excepción relevante.

Cabe hacer notar que los Tratados celebrados por Morulandia y los Estados de Consistinia y Plutorca no contienen limitaciones en lo que se refiere a la transferencia de fondos, mientras que el concluido entre el primer Estado y Camingo sí lo hace. De esta manera, el Banco Central podría imponer limitaciones a los movimientos de capitales camingueses y no podría hacerlo respecto de los propios de inversionistas de Consistinia y Plutorca.

Ahora volvemos a la pregunta, en el evento que las limitaciones fueran impuestas a los inversionistas del Estado de Camingo por el Banco Central de Morulandia y no a los de Consistinia y Plutorca: ¿podrían reclamar los inversionistas del primer Estado (Camingo) un trato más favorable, vale decir, que dichas limitaciones no le fueran aplicables, o que en el caso que ellas procediesen, fueran acompañadas por una indemnización? ¿Influye en algo que los Tratados celebrados con Consistinia y Plutorca hayan sido suscritos en 1991 y que el Tratado celebrado con Camingo haya sido celebrado diez años después?

El presente trabajo intentará entregar elementos para responder a estas preguntas por medio de un análisis legal de la estructura de la Cláusula de Nación Más Favorecida y de su rol en el régi- 
men del Derecho Internacional de Inversiones. Con todo, podemos anticipar nuestra posición: si la CNMF no ha sido redactada con excepciones específicas, ella podrá atraer las condiciones más favorables contenidas en tratados con terceros Estados suscritos con anterioridad al instrumento que sirve para su invocación. De esta forma, los tratados de Inversión con una CNMF sin limitaciones tendrían un efecto no advertible a simple vista: consolidarían los elementos de política económica de los Estados vertidos en ellos a la hora de su entrada en vigencia. Si se considera que es absolutamente legítimo un cambio en la misma, el escenario para Estados como Morulandia es particularmente complicado a la hora de enfrentar golpes de timón en su estrategia de desarrollo.

El artículo comienza con una introducción de la CNMF, abordando su importancia y destacando las diferencias que ella asume en el régimen de comercio (en donde se originó) y en el propio de las inversiones. Posteriormente, precisa el ámbito de aplicación de esta disposición, analizando los elementos que permiten invocarla. Luego se destaca la forma específica en la que opera, para más tarde presentar la discusión doctrinal relativa a la atracción de condiciones más ventajosas comprendidas en Tratados Internacionales celebrados con anterioridad. Como se verá, es precisamente su manera de operar, por regla general, la que encierra a los Estados en la política económica expresada por medio de sus Tratados de Inversión en un momento determinado del tiempo.

\section{INTRODUCIENDO}

\section{la Cláusula de Nación Más Favorecida}

La CNMF es considerada como uno de los pilares del derecho comercial internacional (Dolzer y Schreuer, 2012: 207). Aun cuando no forma parte del derecho internacional consuetudinario (Dolzer y Schreuer, 2012; Paparinskis, 2013; Acconci, 2005), sino que corresponde a una obligación que debe figurar en los Tratados para poder ser invocada (UNCTAD, 2010), y precisamente por eso, se considera fundamental, entre otras razones, pues permite evitar la discriminación en el tráfico entre distintos Estados.

Fue ese carácter "igualitario" el que conspiró en favor de su incorporación en los modernos Tratados de Inversión, transformándose en una de las cláusulas más usuales (Kürtz, 2004). De acuerdo a la Conferencia de las Naciones Unidas sobre Comercio y Desarrollo (UNCTAD, por sus siglas en inglés), la CNMF ha asumido un rol-junto a la disposición de Trato Nacional- "esencial para promover la 
liberalización”3 (UNCTAD, 2010: 2). De esta manera, ambos estándares "apuntan a asegurar un piso común para la actividad económica de actores nacionales y extranjeros, así como son un prerrequisito para la competencia" ${ }^{4}$ (Schill, 2009: 498499), de manera que juntos "disminuyen las distorsiones económicas en el Estado que recibe la inversión" (Faya, 2008: 89) $)^{5}$. Precisamente por ello, el estándar de Trato Nacional y la Cláusula de Nación Más Favorecida "reflejan el rol crucial que juegan las estructuras competitivas, tanto para una eficiente asignación de recursos como para la eficiencia de las inversiones"6 (Schill, 2009: 503).

No obstante y debido a que no existe un símil del Acuerdo General sobre Aranceles y Comercio (o GATT, por sus siglas en inglés) en el ámbito del Derecho Internacional de Inversiones, la redacción de la CNMF varía, en general, de

Traducción libre del inglés: «essential to fostering liberalization».

4 Traducción libre del inglés: «aim at ensuring a level playing field for the economic activity of foreign and domestic economic actors and area a prerequisite for competition".

5 Traducción libre del inglés: «diminishes economic distortions in a host country».

6 Traducción libre del inglés: «reflect the crucial importance competitive structures play for efficient investment and an efficient allocation of resources». En el mismo sentido, Faya (Faya, 2008).
Tratado en Tratado. Sin embargo, ello no impide -en opinión de los especialistas- que, a falta de disposiciones específicamente destinadas a alterar de manera sustantiva su forma de operación normal, serán su función y alcance original los que prevalecerán (García, 2013; Kürtz, 2004; Faya, 2008). Siguiendo a García (García, 2013), la primera pregunta a responder se refiere a determinar cuál es esa función y alcance original, cuestión de la que nos encargaremos a continuación.

El primer instrumento que debe mirarse para hacerlo es el Proyecto de Artículos sobre Cláusula de $\mathrm{Na}$ ción Más Favorecida de la Organización de Naciones Unidas (ONU, 1972). Aun cuando este nunca se materializó en una convención internacional legalmente vinculante para sus miembros, es usualmente acusado como un punto de referencia que debe ser considerado a la hora de interpretar los Tratados Internacionales que contienen la CNMF (Schill, 2009). Así, el inciso primero del artículo 2 del mencionado documento dispone que "por 'Cláusula de la Nación más Favorecida' se entiende una disposición de un tratado en virtud de la cual uno o más Estado concedentes se obligan a otorgar el trato de la nación más favorecida a uno o más Estados beneficiarios".

Por su parte, el inciso primero del artículo 3 del mismo documento agrega que "por Trato de la Nación 
más Favorecida se entiende un trato otorgado en condiciones no menos favorables que las del trato otorgado por el Estado concedente a cualquier tercer Estado, en una esfera definida de las relaciones internacionales con respecto a determinadas personas o cosas".

De ambas normas fluyen las características generales de la CNMF.

En primer término, la CNMF es una "disposición de un tratado", vale decir, para que opere es necesario que ella se encuentre pactada expresamente por las partes, de modo que no pertenece al derecho internacional consuetudinario, como se indicó con anterioridad.

Esta incluye a un Estado "concedente" (el que se obliga a otorgar el Trato de Nación más Favorecida) y a uno "beneficiario" (el que pasa a ser quien puede exigir dicho trato). Ello no obsta a que los Estados asuman ambas posiciones a la vez, como bien se encarga de aclarar el Proyecto en el inciso segundo del artículo 2.

Ella se rige por el principio de ejusdem generis, que limita su operación. De acuerdo a Faya (Faya, 2008), a través de este:

La materia [en que opera la CNMF] se restringe de dos maneras: en primer término, por medio de la cláusula misma, que siempre se refiere a un asunto específico y, en segundo, por el derecho concedido por el Estado concedente al tercer Estado. Esta situación es similar, aun cuando no idéntica, en lo que toca a los sujetos de interés en virtud de los cuales el Estado beneficiario puede reclamar el Trato de Nación más Favorecida. En el contexto de los Tratados Internacionales de Inversión, el beneficio se refiere, obviamente, a los inversionistas o a sus inversiones (Faya, 2008: 89) ${ }^{7}$.

A ello cabe agregar que el tratado que contiene la CNMF pasa a denominarse "Tratado Base", debido a que "(...) contiene las bases para incorporar el Trato más favorable contenido en un tercer Tratado (...)" (Schill, 2008: 506) .

Tal y como salta a la vista, el Trato de Nación Más Favorecida (concedido en virtud de una CNMF) es relativo y contingente, en la medida que se concede a un

Traducción libre del inglés: "the subject matter is restricted in two ways: first, by the clause itself, which always refers to a certain matter, and secondly by the right conferred by the granting state to the third state. The situation is similar, although not identical, in respect of the subjects in the interests of which the beneficiary state is entitled to claim most favourednation treatment. In the context of IIAs, the benefit is obviously accorded to investors or their investments".

Traducción libre del inglés: “(...) it contains the basis for incorporating more favorable conditions granted in a third-party treaty into the treaty relationship between (...)”. 
Estado particular (y en el caso del derecho de inversiones, a los inversionistas de un Estado específico) en relación al trato que se otorga a un tercer Estado (o a sus inversionistas), cuestión que contrasta con otros estándares, como es el caso del de Trato Justo y Equitativo9.

Antes de revisar más en detalle la forma en que opera la cláusula en el derecho internacional de inversiones, vale la pena hacer presente las prevenciones de los especialistas al respecto, las cuales guardan relación con su origen propiamente comercial.

Así, ellos han subrayado que, sin perjuicio de que mucho se ha escrito en lo que toca a las ventajas de la incorporación de cláusula en los tratados de comercio ${ }^{10}$, el asun-

9 De acuerdo a Acconci, es un standard relativo, en tanto "presupone una comparación de la manera en que otras inversiones extranjeras (...) son tratadas por el Estado receptor en una situación similar" (Acconci, 2005: 1). Traducción libre del inglés: "presuppose comparison with the way other foreign investments (...) are dealt with by the host State in a like situation".

De acuerdo a Kürtz, el rol de la cláusula en materia de comercio internacional ayuda a prevenir la imposición de aranceles discriminatorios que distorsionarían sensiblemente los precios, cuestión que “(...) cuenta tanto con implicancias en el bienestar doméstico como en el global" (Kürtz, 2004: 863). Traducción libre del inglés: «(...) both global and domestic welfare implications». Así, de acuerdo al mismo autor, la CNMF en materia to no es tan sencillo en materia de inversiones (Kürtz, 2004) ${ }^{11}$.

Además, la doctrina agrega que las diferencias anteriormente acusadas no son solo de fundamentos, sino que también alcanzan al contenido de la disposición en la práctica. Así, Faya subraya que mientras que en lo relativo a régimen de comercio, las medidas que pueden afectar a un Estado o beneficiar a otro se encuentran más bien limitadas y se relacionan, principalmente, con ventajas o desventajas cuantitativas en materia de aranceles; en términos de inversiones, el espectro es particularmente amplio, en tanto las medidas que pueden poner en movimiento la cláusula son, en este caso, innumerables (Faya, 2008) o como lo ha señalado otro autor, son de una variedad "voraz" (Cole, 2012).

El problema del "trasplante" de la CNMF desde el régimen de comercio al de inversiones se

comercial permite el uso eficiente de recursos.

11 Sin perjuicio de ello, Acconci (Acconci, 2005) subraya que varias razones explican la inclusión de la CNMF en los tratados internacionales de inversión. Entre ellas, cabe señalar la importancia de la inversión extrajera a nivel mundial, la complementariedad entre ella y el comercio internacional, los cambios de dirección en los flujos de inversión extranjera, la competencia de los Estados por recibir nuevos flujos y, así, la necesidad de seguridad y certeza que encuentran los inversionistas extranjeros. 
encuentra también en su interpretación. Así, de acuerdo a Cole, una interpretación teleológica de ella (es decir, una que sostenga que el objetivo de la cláusula es eliminar la discriminación basada en la nacionalidad de los inversionistas en un mercado particular) podría llevar a que los tribunales arbitrales “(...) dejasen de lado los argumentos técnicos a la hora de analizar la forma de operar de la cláusula y la interpretasen simplemente de la manera en que elimine la discriminación en los mercados de la forma más eficiente" (Cole, 2012: 540-541)12. Todavía más, Dolzer y Schreuer agregan a este respecto que "cuando la regla de la nación más favorecida se aplica en dicho contexto [en el campo de la inversión extranjera] de una forma mecánica, el efecto puede ser el reemplazar la sustancia negociada del Tratado más que el añadir un elemento de cooperación" (Dolzer y Schreuer, 2012: 207)13.

Estas razones han militado en favor de que cierto grupo de ana-

12 Traducción libre del inglés: «(...) to lay aside technical arguments as to the operation of the clause and simply interpret it in the way that will most effectively eliminate market discrimination».

13 Traducción libre del inglés: «when the MFN rule is applied in such a context [el campo de la inversion extranjera] in a mechanical manner, the effect may be to replace the negotiated substance of the treaty rather than to add an element of cooperation». listas subraye que “(...) no es claro que los fuertes argumentos políticos y económicos (y así, el fundamento de legitimidad) propios del Trato de Nación más Favorecida en materia de comercio (...) sea transportable al contexto de inversiones" (Kürtz, 2004: 866) $)^{14}$.

Sin embargo, no todas las voces son críticas. Así, por ejemplo, Schill sostiene que la incorporación de la CNFM en Tratados de Inversión ayuda a reducir "conflictos y tensiones internacionales", en tanto previene que los Estados funden su política comercial y de inversiones, en la construcción de bloques cerrados (Schill, 2008: 501). El mismo autor agrega, en este sentido, que este estándar “(...) permite un marco de referencia más transparente para las relaciones internacionales de inversión, porque la adhesión a complicadas y costosas reglas relativas al origen del capital para determinar el estándar de protección aplicable" (Schill, 2008: 508) ${ }^{15}$. En definitiva, por medio de su vocación

14 Traducción libre del inglés: «(...) it is by no means clear that the strong economic and political case (and hence, touchstone for legitimacy) of MFN treatment as a counter to trade and, especially, tariff discrimination is automatically transportable to the investment context».

15 Traducción libre del inglés: «(...) allows for a more transparent framework for international investment relations because it dispenses with the necessity to adhere to complicated, and thus costly, rules on the origin of 
igualitaria, la CNMF aportaría a reducir los costos de transacción involucrados en la actividad.

Siguiendo esta línea de argumentación, la importancia de la CNMF en el derecho de inversiones se vuelve aún más crítica, en la medida que este régimen se ha desarrollado de una manera atomizada (UNCTAD, 2010). En tanto este tomó cuerpo principalmente por medio de la celebración de Tratados Bilaterales, como los Tratados Bilaterales de Inversión, de los cuales existían 2.857 en 2012 (UNCTAD, 2010), y considerando que ellos pueden diferir en su redacción, producto de las negociaciones específicas que sigan los Estados parte (UNCTAD, 2010), la CNMF serviría como dispositivo de "multilateralización en la práctica" de sus compromisos (Schill, 2008), extendiendo el trato que un Estado otorga a inversionistas de otro Estado a los propios de otro país, bajo el tratado que incluye la $\mathrm{CNMF}^{16}$. Desde este punto de vista, la cláusula en este régimen "puede servir para armonizar el derecho bajo el cual operan inversionistas

capital in order to ascertain the applicable standard of protection».

16 Incluso, yendo más lejos Chalamish (Chalamimsh, 2009) indica que por medio de la inclusión de la CNMF en los Tratados Bilaterales de Inversión se construye una red compleja de instrumentos en la materia que se asemejaría a un Tratado Multilateral. de distintos Estados" ${ }^{17}$ (Cole, 2012: 539-540).

El ÁMBito DE APLICACIÓN de la Cláusula de Nación MÁs FAVORECIDA EN EL DERECHO DE INVERSIONES

Asumiendo que no existen excepciones relevantes, y pese a las diferencias de redacción, seguiremos la posición sugerida por García (García, 2013), en lo que toca a considerar su redacción estándar a la hora de analizar sus efectos. Ejemplo de este tipo de redacción es la contenida en el segundo numeral del artículo cuarto del Acuerdo entre la República de Chile y la República de Hungría para la Promoción y Protección Recíproca de las Inversiones, en la que se lee:

Cada Parte Contratante otorgará a las inversiones de inversionistas de la otra Parte Contratante, efectuadas en su territorio, un trato no menos favorable que aquel otorgado a las inversiones de sus propios inversionistas, o a inversionistas de un tercer país, si este último trato fuere más favorable.

Como salta a la vista, el texto anterior expresa los elementos ge-

17 Tradducción libre del inglés: «can serve to harmonize the law under which foreign investors from different states operate». 
nerales indicados previamente: la disposición de trato más favorecido habría sido pactada (naturaleza convencional), tendría una orientación "contingente" y "relativa", y se limitaría a un ámbito específico (al trato que se conceda a los inversionistas o a las inversiones de terceros Estados, en contraste del otorgado a los Estados parte).

Sin embargo, la doctrina suele agregar otro elemento, el que por lo general se encuentra ausente de la redacción específica de su texto (como ocurre en el caso del que ya vimos). Así, para que opere la CNMF, es necesario que se verifique un elemento material que permita la comparación entre los inversionistas que son tratados más favorables de los que no lo son (UNCTAD, 2010). Este elemento material se refiere a que los inversionistas se encuentren en "circunstancias similares" ("like circumstances"). Sobre el particular, la UNCTAD explica que

El conceder Trato de Nación más Favorecida no requiere que todos los inversionistas extranjeros sean tratados de igual manera, sin considerar las circunstancias o sus actividades de negocios. El diferente trato se justifica entre los inversionistas que no pueden compararse legítimamente, por ejemplo, que no operan en el mismo sector económico o que no tienen la misma estructura corporativa (...). Por ejemplo, el trato de Nación más Favorecida no impide que los Estados receptores concedan distinto trato a actividades de diferentes sectores de la economía, ni que ellos diferencien empresas de diferente tamaño ni entre empresas con o sin socios domésticos (UNCTAD, 2010: 26).

Precisamente por ello, la misma Comisión sostiene que el interpretar la cláusula en un sentido diferente “(...) distorsionaría el sentido y la naturaleza de la Cláusula de Nación más Favorecida".

Desde otro punto de vista, para que opere la CNMF requiere que se otorgue un trato diferente a los inversionistas y que dicho trato sea favorable para uno y desfavorable para el otro, desde un punto de vista objetivo (Schill, 2008). Asimismo, dicho "tratamiento" comprende cualquier medida adoptada u omitida por el Estado que recibe la inversión, la cual puede asumir la forma de leyes, regulaciones o acciones/omisiones determinadas.

Finalmente, la UNCTAD destaca que el ámbito de aplicación de la CNMF se encuentra igualmente limitado por "libertad contractual", de manera que "si un Estado receptor concede privilegios especiales o incentivos a un inversionista particular por medio de un contrato, no existiría obligación respecto de 
la Cláusula de Nación más Favorecida en tratar a otros inversionistas extranjeros de la misma manera" 18 (UNCTAD, 2010: 29).

\section{Automática E}

IMPORTADORA: LA FORMA DE operar de la Cláusula de NACIÓN MÁS FAVORECIDA EN EL DeRECho DE INVERsiones

Teniendo presente el alcance de la cláusula, ahora podemos referirnos a la manera en cómo opera. En este sentido, existe un consenso generalizado en que la CNMF lo hace de manera automática (Dolzer y Schreuer, 2012; Schill, 2008), cuestión que, de acuerdo a Cole, puede entenderse de dos maneras diferentes.

En primer término, como un "derecho a exigir" ("righ to claim"), y en segundo, como una "obligación instantánea". De acuerdo a nuestro autor, la primera alternativa consiste en que " (...), tan pronto y como se concede un trato más favorable a un tercer inversionista, el beneficiario de la Cláusula de Nación más Favorecida adquiere el 'derecho a exigir' un trato equivalente para sí. Esto significa que no surge una

18 Traducción libre del inglés: «if a host country grants special privileges or incentives to an individual investor through a contract, there would be no obligation under the MFN treatment clause to treat other foreign investors equally». obligación inmediata para el Estado que concede un trato más aventajado a otro inversionista, pero una vez que el beneficiario exige un trato equivalente, este debe ser concedido" 19 (Cole, 2012: 569). En otras palabras, esta interpretación requiere un comportamiento activo de parte del inversionista (o más precisamente, de acuerdo a Cole, de su Estado) que se encuentra en una posición desmejorada, producto de una medida adoptada por el Estado receptor de la inversión.

Por otro lado, en lo que toca a entender la manera en que funciona la CNMF como una "obligación instantánea”, Cole acota que esto supone que el trato más favorable concedido por un Estado a un inversionista debe ser extendido automáticamente al inversionista de otro Estado que cuenta con un tratado de inversión que incluye la CNMF (en la medida en que se cumplan los demás requisitos).

Así, "cualquier exigencia que efectúe [el inversionista afectado] en contra del Estado [receptor] (...)

19 Traducción libre del inglés: «(...) as soon as more favorable treatment is provided to a third party, the beneficiary of the MFN clause gains the «right to claim» equivalent treatment for itself. That is, no immediate obligation arises for the state providing the treatment to the third state to also provide it to the beneficiary of the MFN clause, but once the beneficiary requests equivalent treatment, it must be provided». 
respecto de beneficios que debió haber recibido bajo la Cláusula de Nación más Favorecida se entenderá concedido al momento que el trato más favorable fue otorgado (...) al otro inversionista" ${ }^{20}$ (Cole, 2012: 570).

Siguiendo a nuestro autor, si bien es la primera interpretación la que otorga más policy space y predictibilidad al Estado receptor, la mayoría abrumadora de los laudos arbitrales que han analizado el problema, han seguido la segunda. Ello se debe, en su opinión, a la inclusión expresa en la mayor parte de los Tratados Internacionales de Inversión de un mecanismo directo para la resolución de controversias entre el inversionista afectado y el Estado receptor. Así, a su juicio, la separación entre las partes del tratado y las partes de una eventual controversia milita en contra de la interpretación del "derecho a exigir”, en tanto según ella sería el Estado del inversionista afectado el que debería presentar la reclamación correspondiente, en busca de un trato más favorable para este último. De esta forma, pese a su inconveniencia (para los Estados receptores de la inversión),

20 Traducción libre del inglés: «any claim it makes [the affected investor] against [the host] State (...) for benefits it should have received under the MFN clause will be backdated to the moment the more favorable treatment was given to (...) the other investor».
Cole subraya que es la segunda interpretación la que se corresponde con la Cláusula de Nación más Favorecida.

Sin perjuicio de que la UNCTAD (UNCTAD, 2010) y comentaristas como Faya (Faya, 2008) son particularmente críticos en lo que se refiere a la "importación" de condiciones más favorables de un tratado a otro por medio de la $\mathrm{CNMF}^{21}$, Schill subraya que la gran mayoría de los laudos arbitrales que la han aplicado, han determinado que ella opera de esta forma (Schill, 2012). De acuerdo al mismo autor:

La importación de condiciones sustantivas más favorables concedidas en otro tratado de inversión es consistente con la racionalidad económica de las Cláusulas de Nación más Favorecida, en tanto iguales condiciones y estándares de trato para inversionistas de distintas nacionalidades son esenciales para nivelar las condiciones de competencia y para una asignación eficiente de los recursos. Aún más, la incorporación de derechos

21 Sin embargo, cabe destacar que lo discutido por ambos se refiere específicamente a un aspecto de esta forma de operar. De acuerdo a ellos, lo que ocurre no es que la CNMF permita atraer las disposiciones de uno u otro Tratado (pues, por sí mismas, no serían ni más ni menos favorables), sino que por medio de ella se puede atraer un "trato" que en el caso específico y materialmente es más favorable. 
sustantivos más favorables basados en las CNMF, muestra que ellas son una herramienta para la multilateralización y armonización de estándares sustantivos para la protección de inversiones. Las cláusulas no solo extienden y multilateralizan las condiciones más favorables de tratados con terceros Estados, sino que también desalientan futuros esfuerzos de circunscribir las relaciones de inversión entre los Estados de una manera bilateral ${ }^{22}$ (Schill, 2012: 521).

Así, a la vez que puede notarse que Schill toma distancia de las reflexiones de la UNCTAD y de las de Faya, concluye que este tipo de cláusulas “(...) armonizan la protección de las inversiones al

22 Traducción libre del inglés: «importing more favorable substantive conditions granted in third-country BITs comports with the economic rationale of MFN clauses, as equal investment conditions and standards of treatment for investors of different nationalities are essential to equal competition and to an efficient allocation of resources. Furthermore, the incorporation of more favorable substantive rights based on MFN clauses shows that the clauses are a tool for the multilateralization and harmonization of substantive standards of investment protection. The clauses not only extend and multilateralize more favorable conditions from third-country BITs, but also deter future efforts to contain inter-State investment relations on a bilateral basis». nivel más alto disponible" (Schill, 2012: 521).

No obstante lo anterior, y tal como se destacó al comienzo de este trabajo, la situación no es tan clara a la hora de la importación de disposiciones procedimentales de un tratado a otro, lo cual se debe, entre otras razones, al silencio que guardan este tipo de instrumentos internacionales al respecto (Freyer y Herlihly, 2005). En tanto este problema excede el objeto de este trabajo, evitaremos referirnos a las posiciones de la doctrina a su respecto y a los laudos arbitrales que han lidiado con él, sin perjuicio de que utilizaremos como referencia estos últimos, cuando comentemos la aplicación en el tiempo de la cláusula en el acápite que sigue.

\section{ATRAYENDO CONDICIONES}

\section{MÁS FAVORABLES CONTENIDAS EN TRATADOS PREVIOS}

En el ejemplo esbozado al inicio de este trabajo, decíamos que Morulandia (el Estado receptor de la inversión) habría alterado levemente su política de atracción de capitales extranjeros por medio de una modificación incluida en la cláusula de transferencia de fondos (que en los Tratados previos celebrados entre Morulandia y Consistinia y Plutorca no existía). Dicho cambio se habría materializado en el Tratado celebrado entre este país y Camingo, en 2001. 
Nuestra pregunta inicial se refería a si podrían los inversionistas camingueses, en el evento que fueren aplicadas las medidas en contra de sus inversiones contempladas en el Tratado entre su Estado y Morulandia, atraer las condiciones más favorables concedidas a los inversionistas de Consistinia y Plutorca (pues a ellos no se les aplicarían dichas medidas de restricciones de transferencia de fondos), aun cuando ellas se hubiesen materializado en un Tratado concedido diez años antes, previo a la modificación de la política de atracción de capitales extranjeros por parte de Morulandia.

Como también se dijo, este problema no ha encontrado eco (aún) en la jurisprudencia. Sin perjuicio de que ella se ha enfocado particularmente en el problema de la importación de disposiciones procedimentales entre tratados, no se ha preocupado de distinguir las fechas en las cuales los distintos instrumentos han entrado en vigor, pues este no ha aparecido claramente. A continuación reproducimos sumariamente la "red de tratados" (vale decir, identificamos tanto el Tratado Básico como el Tercer Tratado invocado por medio de la CNMF) correspondientes a algunos de los casos más destacados que han recibido la atención del CIADI, señalando sus respectivas fechas de entrada en vigencia para ilustrar el punto.

\section{Red de Tratados}

\begin{tabular}{|l|c|}
\hline Caso & Maffezini v. Reino de España \\
\hline Estado al que pertenece el inversionista & Argentina \\
\hline Tratado Básico & Argentina - España \\
\hline Fecha entrada en vigencia Tratado Básico & $28 / 09 / 1992$ \\
\hline Tercer Tratado & España - Chile \\
\hline Fecha entrada en vigencia Tercer Tratado & $28 / 03 / 1994$ \\
\hline
\end{tabular}

\begin{tabular}{|l|l|}
\hline Caso & $\begin{array}{l}\text { Plama Consortium Limitada v. } \\
\text { República de Bulgaria }\end{array}$ \\
\hline Estado al que pertenece el inversionista & Chipre \\
\hline Tratado Básico & Bulgaria - Chipre \\
\hline Fecha entrada en vigencia Tratado Básico & $18 / 05 / 1988$ \\
\hline Tercer Tratado & Bulgaria - Finlandia \\
\hline Fecha entrada en vigencia Tercer Tratado & $16 / 04 / 1999$ \\
\hline
\end{tabular}


Consolidando la política de inversiones por medio de la Cláusula de Nación...

\begin{tabular}{|l|l|}
\hline Caso & $\begin{array}{l}\text { Asian Agricultural v. República de } \\
\text { Sri Lanka }\end{array}$ \\
\hline Estado al que pertenece el inversionista & Reino Unido \\
\hline Tratado Básico & Reino Unido - Sri Lanka \\
\hline Fecha entrada en vigencia Tratado Básico & $18 / 12 / 1980$ \\
\hline Tercer Tratado & Sri Lanka - Suiza \\
\hline Fecha entrada en vigencia Tercer Tratado & $12 / 02 / 1982$ \\
\hline
\end{tabular}

\begin{tabular}{|l|l|}
\hline Caso & $\begin{array}{l}\text { Siemens A. G. v. República de } \\
\text { Argentina }\end{array}$ \\
\hline Estado al que pertenece el inversionista & Alemania \\
\hline Tratado Básico & Argentina - Alemania \\
\hline Fecha entrada en vigencia Tratado Básico & $8 / 11 / 1993$ \\
\hline Tercer Tratado & Argentina - Chile \\
\hline Fecha entrada en vigencia Tercer Tratado & $01 / 01 / 1995$ \\
\hline
\end{tabular}

\begin{tabular}{|l|l|}
\hline Caso & $\begin{array}{l}\text { Gas Natural v. República de } \\
\text { Argentina }\end{array}$ \\
\hline Estado al que pertenece el inversionista & Reino de España \\
\hline Tratado Básico & España - Argentina \\
\hline Fecha entrada en vigencia Tratado Básico & $28 / 09 / 1992$ \\
\hline Tercer Tratado & Argentina - Estados Unidos \\
\hline Fecha entrada en vigencia Tercer Tratado & $20 / 10 / 1994$ \\
\hline
\end{tabular}

\begin{tabular}{|l|l|}
\hline Caso & $\begin{array}{l}\text { Salini Construttori S. P. A. v. Reino } \\
\text { de Jordania }\end{array}$ \\
\hline Estado al que pertenece el inversionista & Italia \\
\hline Tratado Básico & Italia - Jordania \\
\hline Fecha entrada en vigencia Tratado Básico & $17 / 01 / 2000$ \\
\hline Tercer Tratado (1) & Jordania - Estados Unidos \\
\hline $\begin{array}{l}\text { Fecha entrada en vigencia Tercer Tratado } \\
(1)\end{array}$ & $12 / 06 / 1993$ \\
\hline Tercer Tratado (2) & Jordania - Reino Unido \\
\hline $\begin{array}{l}\text { Fecha entrada en vigencia Tercer Tratado } \\
(2)\end{array}$ & $24 / 04 / 1980$ \\
\hline
\end{tabular}

Fuente: elaboración propia sobre la base de información emanada de CIADE.

Como puede notarse, la dimensión "temporal" del problema que hemos enunciado no ha tenido cabida en la jurisprudencia, pues aún no es llevado ante arbitraje un caso como el hipotético que hemos descrito para Morulandia. La única excepción al respecto parece ofrecérnosla el de Salini Construttori S. P. A. v. Reino de Jordania, el cual describiremos sumariamente solo 
desde la perspectiva relevante para estos efectos.

En dicho caso, el inversionista extranjero invocó subsidiariamente la CNMF contenida en el Tratado celebrado entre su Estado (Italia) y el Reino de Jordania, con el objeto de que se sujetase el conflicto que mantenía con este último país a la competencia del CIADI. Ello se debía a que en el Tratado Base (es decir, en el Tratado entre Italia y el Reino de Jordania) dicho mecanismo se encontraba ausente, cuestión que no era el caso en los tratados celebrados entre el Reino de Jordania y el Reino Unido y entre el primero y los Estados Unidos.

Sin embargo, y tal y como salta a la vista en la tabla resumen anterior, nos encontramos con que el Tratado Base entró en vigencia el 17 de enero de 2000, mientras que los Terceros Tratados lo hicieron el 24 de abril de 1980 y el 12 de junio de 1993, respectivamente. Esta diferencia temporal pasó inadvertida por el Tribunal, aun cuando desechó la aplicación de la cláusula por otras consideraciones.

$\mathrm{Si}$, aparentemente, la jurisprudencia no ofrece una respuesta a este problema, quien sí lo ha hecho es la doctrina. Los bandos se han definido de la siguiente manera: Schill (Schill, 2012), en primer término, indica que no existirían obstáculos para que inversionistas que se encontrasen en la posición de los camingueses de nuestro ejemplo reclamasen el trato más favorable concedido por Estados como el de Morulandia a inversionistas de terceros Estados como los de Consistinia y Plutorca. Cole (Cole, 2012), por su parte, indica que ello no sería posible aunque añade un bemol: la situación sería diferente en el caso que el trato no fuese concedido por medio de un tratado, sino que fuese implementado en la práctica. A continuación revisamos en detalle las posiciones de ambos.

Comenzamos con la posición de Cole, para quien los inversionistas camingueses no podrían servirse de la CNMF contenida en el Tratado entre Camingo y Morulandia (recuérdese, el Tratado Base, vigente desde 2001) para invocar condiciones más favorables dispuestas en Tratados como el celebrado entre Morulandia y Camingo (vigente desde 1991), pues no podría sostenerse que esa haya sido la voluntad de los Estados parte del Tratado Base. De esta manera, si es la intención de los Estados partes la que debe ser analizada cuidadosamente cuando se interpreta la CNMF y su texto ${ }^{23}$, no

23 El argumento de Cole se basa específicamente en la intención de las partes contratantes del tratado. Así, él subraya el elemento correspondiente del artículo 31 de la Convención de Viena sobre Derecho de los Tratados. $\mathrm{Al}$ respecto, indica que "las intenciones subjetivas de los Estados partes de un tratado bilateral de inversión son, por tanto, siempre importantes 
podría seguirse una interpretación distinta “(...) ni siquiera cuando el texto de la CNMF pareciese por sí solo sugerir una aplicación así, en tanto la clara intención de las partes debería considerarse para anular la redacción de la cláusula" ${ }^{24}$ (Cole, 2012: 575).

Cole entiende de esta manera la intención de las partes por la forma en que opera la cláusula. Dijimos previamente -siguiendo al mismo Cole-, que ella lo hace automáticamente, poniendo de cara al Estado que concede el Trato de Nación más Favorecida una "obligación instantánea" respecto del inversionista desmejorado. Recordemos que a este respecto, Cole concluía que así "cualquier exigencia que efectúe [el inversionista afectado] en contra del Estado [receptor] (...) respecto de beneficios que debió haber recibido bajo la Cláusula de Nación más Favorecida, se enten-

a la hora de interpretar sus disposiciones, incluyendo a la CNMF, aun cuando permanezcan subsidiarias a la redacción del tratado mismo" (Cole, 2012: 575). Traducción libre del inglés: «the subjective intentions of the States party to a BIT are, therefore, always important in the interpretation of the provisions of the BIT, including an MFN clause, even though they remain subsidiary to the language of the BIT itself».

24 Traducción libre del inglés: «(...) even where the text of the MFN clause would itself seem to allow such an application, the clear intent of the parties should be taken to override the language of the clause». derá concedida al momento que el trato más favorable fue otorgado (...) al otro inversionista" ${ }^{25}$.

Teniendo eso a la vista y echando mano a nuestro ejemplo ficticio, Cole diría que no puede sostenerse razonablemente que la intención de los Estados de Morulandia y de Camingo haya sido borrar con el codo lo que se escribía con la mano. O si se quiere, en términos técnicos, no podría afirmarse que la intención de esas partes haya sido eliminar la limitación a la transferencia de fondos contenida en su Tratado por medio de la operación de la CNMF, pues dicha eliminación ya habría ocurrido tan pronto y como el Tratado entre Morulandia y Camingo entró en vigencia, de manera que no habría existido un "momento" en el cual las restricciones se habrían encontrado en efecto entre ellas. Así, Cole concluye que "esta situación, no obstante, hace simplemente incomprensible la inclusión de las restricciones en comento dentro del tratado" 26 (Cole, 2012: 576).

25 Traducción libre del inglés: «any claim it makes [the affected investor] against [the host] State (...) for benefits it should have received under the MFN clause will be backdated to the moment the more favorable treatment was given to (...) the other investor».

26 Traducción libre del inglés: «the implausibility that parties to the treaty intended this situation derive not from the fact that the parties to the A-B BIT are receiving treatment other than that promised them in the BIT, as that is an inherent conse- 
Aun más, redobla su argumento subrayando que si se tiene a la vista que los Tratados Bilaterales de Inversión son públicos (vale decir, que su contenido es conocido públicamente), “(...) no sería plausible que los Estados incorporasen una CNMF en su Tratado como una protección en contra de estándares de trato desconocidos contenidos en otros Tratados de Inversión. La información respecto de esos estándares de trato es demasiado accesible" ${ }^{27}$ (Cole, 2012: 577).

quence of the operation of an MFN clause. Rather, the implausibility results because, due to the instantaneous effect of MFN clauses, the removal of the restrictions on the fair and equitable treatment obligation included in the A-B treaty occurred the instant the A-B treaty came into force. That is, there was no point at which the fair and equitable treatment clause expressly negotiated between States A and B was actually in effect between them. Such a situation, however, simply makes incomprehensible the inclusion of the restrictions in question within the treaty».

27 Traducción libre del inglés: «(...) it is simply implausible that states incorporated an MFN clause into their treaty as a protection against unknown already-existing BIT-based treatment. The information on such treatment is simply too easily accessible. To return to the example above, if unrestricted fair and equitable treatment had been discussed in the negotiations between States A and B, State B could have insisted that State A grant some countervailing benefit. However, if it is subsequently incorporated via an MFN clause, no compensation is given,
Precisamente, porque su posición se funda en la naturaleza "pública" de los Tratados Bilaterales de Inversión, nuestro autor subraya que algo distinto ocurre cuando el tratamiento ha sido concedido por medio de la práctica de un Estado (es decir, por medio de medidas concedidas que no se encuentran plasmadas en un Tratado) a inversionistas de terceros Estados. En este caso, la CNFM contenida en el respectivo instrumento internacional podría servir para importar el "mejor trato", incluso si este se había concedido antes de su celebración (Cole, 2012).

Dicho esto, seguimos con la opinión de Schill, quien a diferencia de Cole se pronuncia en favor de la interpretación criticada por este último. Su posición se funda también en la misma manera en que funciona la CNMF y que despunta en su rol "multilateralizador" en el Derecho Internacional de Inversiones. Para analizar dicho rol es necesario que nos detengamos en un ejemplo específico que sugiere Schill, el cual pone de manifiesto la magnitud de la fuerza de gravedad de la cláusula en esta sede.

and State B has effectively granted unrestricted fair and equitable treatment for free. Absent evidence to the contrary, then, it is simply implausible to read an MFN clause in a BIT as referring to already-existing provisions in a third-state BIT». 
Para el efecto, nuestro autor nos llama a suponer que tenemos ahora otros cuatro Estados, con cuatro tratados distintos entre ellos. El Tratado Base (celebrado entre el Estado A y el Estado B) contiene la CNMF, aunque con una excepción específica que se materializa en una desventaja en un ámbito determinado. Supóngase también que el Estado A concede, por medio de otro Tratado, esa ventaja (que no figura en el instrumento ya mencionado) al Estado C. En tanto esa ventaja se encontraría excluida de la órbita de la CNMF del Tratado Base (vale decir, del Tratado entre A y B), los Inversionistas de B no podrían reclamarla. Sin embargo, Schill advierte que esos inversionistas podrían atraer la misma ventaja pese a la excepción, si el Estado A hubiese celebrado un tratado que comprendiese una CNMF sin dicha limitación con un Estado D.

Así, Schill nos dice que "el Estado B podría incorporar el trato más favorable otorgado al Estado C basado en una doble incorporación (o doble derivación) por medio de la CNMF contenida en el Tratado entre A y B, en conjunto con el trato más favorable concedido al Estado D, el que se le extiende por medio de la CNMF contenida en el Tratado celebrado entre el Estado A y el Estado D”28 (Schill, 2012: 526).

28 Traducción libre del inglés: «State B can thus incorporate the more favorable treatment to $\mathrm{C}$ based on a double
Como salta a la vista, para Schill el poder de la CNMF sería tal que le permitiría (vía doble derivación o incorporación) eliminar las propias limitaciones contenidas en su redacción, salvo que las excepciones que se le agregasen fuesen tan sofisticadas y específicas que, advirtiendo su fuerza de gravedad, se encargasen de morigerarla de manera sustantiva.

De esta forma, si para él la CNMF tiene el poder de "purgarse a sí misma" (cuestión que estaría dentro de su esfera de funcionamiento normal), no cabría recurrir a otra supuesta intención de las partes (como lo hace Cole), toda vez que ellas se encontrarían absolutamente conscientes de sus efectos y, con ello, del rol multilateralizador que asumen en la práctica.

Es justamente este argumento el que le permite a Schill pronunciarse en favor de los inversionistas camingueses de nuestro ejemplo. Por ello, indica que este tipo de cláusulas “(...) aseguran que un cierto nivel de protección de las inversiones que fue alcanzado en Tratados de Inversión anteriores resultará más difícil de cambiar por medio de la incorporación de futuros tratados

incorporation (or double derivation) via the MFN clause in the treaty between $\mathrm{A}$ and $\mathrm{B}$ together with the more favorable treatment granted to D which is extended to $\mathrm{D}$ based on the MFN clause in the treaty between A and $\mathrm{D} »$. 
más restrictivos. Las CNFM impiden intentos de reducir los niveles de protección a las inversiones una vez que hayan sido concedidos por un Estado receptor en sus Tratados de Inversión, en tanto las cláusulas le permiten a los inversionistas incorporar estándares más amplios de protección a las inversiones de Tratados de Inversión más antiguos que el mismo Estado receptor ha celebrado" 29 (Schill, 2012: 568). Así, Schill concluye que:

Hasta cierto punto, las CNMF encierran, por lo tanto, a los Estados en el nivel más favorable de protección de inversiones alcanzados en cierto momento del tiempo y proyectan este nivel hacia el futuro. En suma, las CNMF forman parte del proceso en marcha de multilateralización de las relaciones de inversión internacionales y constituyen así una base normativa explícita

29 Traducción libre del inglés: «(...) secure that a certain level of investment protection that was reached in earlier investment treaties will be more difficult to change by introducing more restrictive BITs in future investment treaties. MFN clauses impede attempts to withdraw from the level of investment protection once granted by a host State in its investment treaties, as the clauses enable investors to incorporate possibly broader standards of investment protection from older investment treaties the same State has concluded». para su desarrollo ${ }^{30}$ (Schill, 2012: 568-569).

La respuesta afirmativa de Schill en favor de los inversionistas camingueses es respaldada también por los comentarios al Proyecto de Artículos sobre Cláusula de Nación más Favorecida indicado previamente (United Nations, 1978). Específicamente, en el numeral 2 al comentario del artículo 20 se lee que: "una Cláusula de Nación más Favorecida, sin redacción en contrario, atrae obviamente los beneficios concedidos a un tercer Estado, tanto antes como después de la entrada en vigencia del tratado que la contenga" ${ }^{31}$.

Los comentarios citan el siguiente argumento para justificar su posición:

(...) En tanto el propósito de la cláusula es ubicar al Estado beneficiario en igual pie que ter-

30 Traducción libre del inglés: «to a certain extent, MFN clauses therefore lock States into the most favorable level of investment protection reached at one point of time and project this level into the future. In sum, MFN clauses therefore form part of the ongoing process of multilateralizing international investment relations and constitute one of the explicit normative bases of this development».

31 Traducción libre del inglés: «a mostfavoured-nation clause, unless otherwise agreed, obviously attracts benefits extended to a third State both before and after the entry into force of the treaty containing the clause». 
ceros Estados, sería un acto de mala fe el continuar esa igualdad a futuras situaciones legales. No puede considerarse que exista una cláusula "pro futuro" o una cláusula dirigida hacia el pasado a menos que sea redactada, inequívocamente, de esa manera. De otro modo, la cláusula debe otorgar al beneficiario todas las ventajas concedidas tanto en el pasado como en el futuro ${ }^{32}$.

En suma, los argumentos de esta posición se fundan no solo en la propia estructura de la cláusula (y su rol multilateralizador en la práctica) sino también, precisamente por ello, en la intención de las partes que la pactaron y en el principio de buena fe que la sostiene.

\section{Evaluando \\ LOS ARGUMENTOS}

No son pocas las críticas que pueden hacérsele a la posición de Schill, además de las contenidas en los argumentos de Cole. Tal vez las

32 Traducción libre del inglés: «(...) since the purpose of the clause is to place the beneficiary State on an equal footing with third States, it would be an act of bad faith to continue that equality to future legal situations. A pro futuro clause or a clause directed towards the past cannot be deemed to exist unless it is worded in unequivocal fashion. Otherwise, the clause must extend to the beneficiary all advantages granted both in the past and in the future». más importantes se refieren a las relativas a las técnicas de interpretación de los Tratados, en las cuales nos centraremos sumariamente.

Como bien expone Ishikawa:

(...) La tarea de un Tribunal, no obstante, no es expresar sus opiniones respecto del multilateralismo o bilateralismo del régimen de Tratados de Inversión al interpretar la CNMF, sino interpretar el Tratado dado de acuerdo con las reglas de interpretación establecidas. Aún cuando es innegable que una CNMF tiene la función de armonizar los estándares entre varios Tratados de Inversión, esas consideraciones de política son relevantes solo en la medida que coadyuvan a la aplicación de las reglas de interpretación ${ }^{33}$ (Ishikawa, 2015: 135).

Para el efecto, la autora nos llama a considerar la regla general

33 Traducción libre del inglés: "with respect, however, a tribunal's task is not to reflect its view on the multilateralism/bilateralism of the investment treaty regime in interpreting the MFN clause but to interpret the given treaty in accordance with established rules of treaty interpretation. While it is undeniable that an MFN clause has the function of harmonising the standards among various investment treaties, such policy considerations are relevant only to the extent that they support the application of the rules of interpretation». 
de interpretación de los Tratados contenida en el Artículo 31 de la Convención de Viena sobre el Derecho de los Tratados. Como es sabido, dicho artículo dispone que los Tratados deben interpretarse "de buena fe, conforme al sentido corriente que haya de atribuirse a los términos del Tratado en el contexto de estos y teniendo en cuenta su objeto y fin". Luego de agregar los elementos que deben ser considerados como parte del contexto, la misma disposición establece que además de este también deben considerarse los acuerdos posteriores entre las partes, así como sus prácticas y, además, “toda norma pertinente de derecho internacional aplicable en las relaciones entre las partes". Asimismo, la mencionada norma concluye indicando que "se dará a un término un sentido especial si consta que tal fue la intención de las partes".

Desde este punto de vista, la pregunta pertinente es considerar si las reglas de interpretación nos obligan a tomar partido, en términos generales, por la posición de Cole. A nuestro juicio, si la CNFM contiene tanta fuerza como para atraer condiciones más favorables, pese a excepciones expresas en su redacción por medio de la "doble derivación" o "doble incorporación" sugerida por Schill, no puede sino concluirse, por regla general, que si las partes no hubiesen deseado dicho efecto (o la posibilidad de atracción de condiciones más favorables contempladas en Tratados celebrados previamente al Tratado Base) lo hubieran pactado concretamente.

Así, la omisión de determinadas circunstancias (como sugiere Ishikawa, pero desde la posición contraria a la que defendemos) permitiría establecer que las partes tuvieron la intención de que la CNMF operase con toda su potencia. En otras palabras, sería la propia y real intención de las partes la que permitiría minar la "supuesta" intención de las mismas propuesta por Cole.

Esta postura se ve reforzada por el "objeto y fin" del tipo de Tratados que se analiza, que no es otro que el de la protección de las inversiones dentro del territorio del Estado receptor ${ }^{34}$. De esta manera, insistimos, la balanza tendería a inclinarse en favor de los inversionistas camingueses ${ }^{35}$.

34 En contra de esta forma específicamente favorable a los inversionistas de interpretar el objeto y finalidad de los Tratados Bilaterales de Inversión, véase Thulasidhass (2015).

35 Sin perjuicio de ello, Ishikawa aduce otro argumento en contra de la posición de Schill. El artículo 31 de la Convención de Viena no agotaría las herramientas interpretativas de los Tribunales, sino que ellas se extenderían a "otras reglas de interpretación (...) que son ampliamente aceptadas por Cortes y Tribunales Internacionales, incluyendo los principios de interpretación eficaz, interpretación con- 
Desde este punto de vista, el tribunal no estaría obligado a recurrir a consideraciones políticas respecto del rol de la CNMF en el Derecho de Inversiones para resolver casos como el de nuestro ejemplo. Así, ese rol multilateralizador sería más "un efecto" de la manera en cómo la cláusula opera, un efecto deseado por las partes, por lo demás, si se tiene a la vista -insistimos- la tesis de la doble derivación aportada por Schill.

De esta forma, serían las propias reglas de interpretación de los Tratados y no consideraciones de política, las cuales permitirían argumentar desde este punto de vista.

\section{Conclusiones}

Como hemos visto, todo parece apuntar a que la CNMF contenida en los Tratados Bilaterales de Inversión minaría sensiblemente la posibilidad de que Estados, como Morulandia, modificasen sus políticas relativas a la inversión extran-

temporánea e interpretación evolutiva”. (Ishikawa, 2015: 136). Traducción libre del inglés: «in addition, there are other interpretative rules that are not specifically mentioned in the VCLT but are widely accepted by international courts and tribunals, including the principles of effective interpretation, contemporaneous interpretation and evolutive interpretation». Es justamente el primero de estos principios del que echa mano con miras a distanciarse de interpretaciones como la de Schill. jera, consolidando las condiciones ofrecidas a los capitales foráneos en un momento determinado del tiempo.

Para conseguir esta respuesta, revisamos tanto la estructura de la cláusula, su ámbito de aplicación así como la manera misma en que opera, cuidando referirnos a la problemática relacionada con la intención de las partes, según el artículo 31 de la Convención de Viena sobre el Derecho de los Tratados.

Claramente, de cara a los inversionistas, la CNMF se mostraría como una herramienta particularmente útil, pues como hemos visto, sería un instrumento eficaz para reducir los costos de transacción en la colocación de sus capitales a lo largo del globo, lo que sumado al mecanismo de solución de controversias que ofrecen los Tratados de Inversión, los pondría en un pie particularmente ventajoso a la hora de hacer valer sus derechos: ellos no solo podrían litigar directamente en un foro "neutral" (el CIADI) en contra de los Estados receptores, sino también podrían hacerlo echando mano a las condiciones sustantivas aplicables más ventajosas posibles, en la medida que se cumpliesen los requisitos de operación de la CNMF que ya hemos visto.

Por otro lado, de cara a los Estados, una CNMF amplia y sin excepciones (como la que suele abundar en los Tratados celebrados 
durante los últimos veinte años del siglo $\mathrm{XX}$ ) se muestra particularmente opuesta a una cualidad que puede considerarse absolutamente deseable, tanto de un régimen internacional de comercio como de uno de inversiones: la capacidad de los Estados para revisar y modificar sus políticas en la materia.

Dicha capacidad es importante no tanto desde el punto de vista de la soberanía de los Estados para modificar sus decisiones, sino porque puede ser de interés desde el mismo marco de la promoción del desarrollo económico. En este sentido, Unger se ha referido a ella en lo que toca al régimen internacional de comercio, pero no existen razones que impidan ampliar sus reflexiones al régimen internacional de inversiones. Así, él subraya que “(...) el mejor tipo de libre comercio será el que asocie más libre comercio con más oportunidad para la autorevisión" (Unger, 2011: 116), en tanto la autorevisión permitiría la experimentación de diferentes formas de combinar los factores de producción que, a su vez, podría servir de base para el reforzamiento del desarrollo.

De esta manera, estimamos que una alternativa prudente para abordar el problema planteado en este trabajo es que se renegocien los Tratados que contienen la CNMF, dando el lugar que le corresponde a la autorevisión (explícita y específicamente) en el cuerpo de los mismos. Estados Unidos y el Reino Unido han seguido este camino, en lo que se refiere a aclarar si ella permite o no atraer condiciones relativas a la solución de controversias (Vessel, 2007). Lo propio ha hecho Argentina y Panamá, por medio del intercambio de notas diplomáticas sobre la misma materia (Parker, 2012). Entonces, bien podría hacerse lo mismo en lo que toca a la atracción de condiciones más favorables contenidas en Tratados Internacionales celebrados previamente. Como se vio, el asunto no es trivial y dotaría a los Estados de la flexibilidad necesaria para afrontar los desafíos del futuro, sin minar la seguridad jurídica perseguida por los capitales extranjeros en el desarrollo de sus inversiones.

\section{Bibliografía}

Acconci, P. (2005). The Most-FavouredNation Treatment and International Law on Foreign Investment. [Versión electrónica]. Transnational Dispute Management, Vol. 2, núm. 5, pp. 1-33. Recuperado el 11 de marzo de 2014 de: http://www.transnationaldispute-management.com/article. asp?key $=604$

Acuerdo entre la República de Chile y la República de Hungría para la Promoción y Protección Recíproca de las Inversiones. Recuperado el 17 de noviembre de 2015 de: http:// investmentpolicyhub.unctad.org/ Download/TreatyFile/684

Chalamimsh, E. (2009). The Future of Bilateral Investment Treaties: A De Facto Multilateral Agreement? Broo- 
klyn Journal of International Law, Vol. 34, núm. 2, pp. 304-354.

Cole, T. (2012). The Boundaries of Most Favored Nation Treatment in International Investment Law. Michigan Journal of International Law, Vol. 33, pp. 537-586.

Convención de Viena sobre el Derecho de los Tratados. Recuperado el 19 de noviembre de 2015 de: http://www. leychile.cl/Navegar?idNorma=12889

Dolzer, R. \& Schreuer, C. (2012). Principles of International Investment Law. Oxford: Oxford University Press.

Egli, G. (2007). Don`t Get Bit: Addressing ICSID's Inconsistent Application of Most-Favored-Nation Clauses to Dispute Resolution Provisions. Pepperdine Law Review, Vol. 34, núm. 4, pp. 1045-1084.

Faya, A. (2008). The Most-FavoredNation Clause in International Investment Agreements. A Tool for Treaty Shopping? Journal of International Arbitration, Vol. 25, núm. 1, pp. 89-102.

Freyer, D. \& Herlihly, D. (2005). Most-Favored-Nation Treatment and Dispute Settlement in Investment Arbitration: Just How "Favored" is "Most-Favored"? ICSID Review, vol. 20, núm. 1.

García, I. (2013). Arbitraje de Inversión: La Cláusula de la Nación Más Favorecida en Derechos Adjetivos. México: Universidad Nacional Autónoma de México.

Ishikawa, T. (2015). Interpreting the Most-Favoured-Nation Clause in Investment Treaty Arbitration: Interpreting as a Process of Creating an Obligation?, en Sampford, Ch. et al. (ed.), Rethinking International Law and Justice, pp. 127-148. Vermont: Ashgate.

Kurtz, J. (2004). The MFN Standard and Foreign Investment. An Uneasy Fit? The Journal of World Investment and Trade, Vol. 5, núm. 6, pp. 861-886.
Organización de Naciones Unidas (1972). Tercer informe sobre la Cláusula de la Nación más Favorecida, por el Sr. Endre Ustor, Relator Especial. Proyecto de artículos 1 a 5 y comentarios. Recuperado el 24 de noviembre de 2015 de: http://legal.un.org/ilc/documentation/spanish/a_cn4_257_add1.pdf Paparinskis, M. (2013). MFN Clauses and International Dispute Settlement: Moving beyond Maffezini and Plama? ICSID Review, Foreign Investment Law Journal, Vol. 28, núm. 2, pp. 14-58.

Parker, S. (2012). A BIT at a Time: The Proper Extension of the MFN Clause to Dispute Settlement Provisions in Bilateral Investment Treaties. Arbitration Brief, Vol. 2, núm. 1, pp. 30-63.

Schill, S. (2009). Mulitilateralizing Investment Treaties through MostFavored-Nation Clauses. Berkeley Journal of International Law, Vol. 27, núm. 2, pp. 496-569.

Sornarajah, M. (2010). The International Law on Foreign Investment. Cambridge: Cambridge University Press.

Thulasidhass, P. R. (2015). Most-Favoured-Nation Treatment in International Investment Law: Ascertaining the Limits through Interpretative Principles. Amsterdam Law Forum, Vol. 7, núm. 1, pp. 3-24.

Unger, R. (2011). La Reinvención del Libre Comercio: La división mundial del trabajo y el método de la economía. Buenos Aires: Fondo de Cultura Económica.

United Nations Conference on Trade and Development (2010). Most-Favoured Nation Treatment. UNCTAD Series on Issues in International Investment Agreements II. New York and Geneva.

United Nations (1978). Draft Articles on most-favoured-nation clauses with commentaries. Recuperado el 24 de noviembre de 2015 de: http://legal. 
un.org/ilc/texts/instruments/english/ commentaries/1_3_1978.pdf

Vessel, S. (2007). Clearing a Path Through a Tangles Jurisprudence: Most-Favored-Nation Clauses and Dispute Settlement Provisions in Bilateral Investment Treaties. The Yale Journal of International Law, Vol. 32, núm. 125, pp. 125-189. 